\title{
Reference Communication: Commonalities in the Worlds of Medicine and Librarianship
}

\section{Rachael Naismith}

\begin{abstract}
Communication between physician and patient is similar to communication between librarian and the library user in many ways. Reference and medical interviews constitute an effort on the part of the professional to both assess an individual's needs and explain a system that may seem complex and new to that individual. A series of issues is discussed, from the standpoint of both the physician's office and the reference desk. This paper presents a series of communication issues and outcomes, describing each as it applies to the physician's office and the reference desk. Avenues for improving communication are suggested.
\end{abstract}

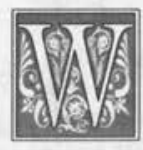

hat we have here is a failure to communicate." This famous line from the movie Cool Hand Luke states a problem that is basic to human interaction. What are the results of a failure to communicate? The reference interview is an arena in which communication failure can have a powerful negative effect on results. The medical interview is another such arena, one in which researchers have studied the results of communication failure in detail. These published results fall under the categories of recall, compliance, medical outcome, and satisfaction. In order that librarians can learn from experts in another field, this paper examines the question of communication problems through a comparison of the reference interview with the medical interview. I want to note that after this article was accepted for publication, a related article appeared in print, Carolyn Radcliff's "Interpersonal Communication with Library Patrons: Physician-Patient Research Models." Radcliff's article offers additional insight into a number of the concepts discussed here.

In the aspect of communication, the relationship between librarian and library user shares certain commonalties with that of physician and patient. Reference and medical interviews entail both finding out information and giving out information. The interviewer often begins by knowing little or nothing about the interviewee's problem, situation, or background. The physician and librarian typically have a limited amount of time to put a person at ease and ascertain his or her

Rachael Naismith is Senior Reference Librarian at the Babson Library at Springfield College, Springfield, Massachusetts. She was Head of Reference Services at the Miller Nichols Library at the University of Kansas City at the time this paper was written. 
needs, which the person may obscure, hide, omit, or have difficulty expressing.

After the complex task of question negotiation, the person's needs must be matched with the resources at hand, or the person referred elsewhere. To impart information, both physician and librarian are often faced with the task of explaining a complex system to people who may lack their specialized knowledge. In his renowned article on question negotiation, Robert Taylor calls the reference interview one of the most complex acts of human communication. In a description that can be applied to the medical interview as well, he writes, "In this act, one person tries to describe for another person not something he knows, but rather something he does not know." 2

The main focus of this paper is on the physician's or librarian's attitude and behavior rather than that of the patient and library user. Because of space limitations, nonverbal communication is not discussed. The format of this paper is to discuss a series of communication issues and outcomes, describing each as it applies to the physician's office and the reference desk.

\section{A Failure to Communicate}

An examination of medical literature for the past twenty-five years reveals a wealth of research on the problems inherent in the communication between physician and patient. Library literature also reveals a similar emphasis on the reference interview. One recent article discussed the physician-patient communication process in terms of its relevance to librarians, but the authors admit it was a limited review and cited no library articles. $^{3}$

In contrast to the Plain English movement, which calls for medical and legal communications to be made comprehensible to the layperson, there seems to be no comparable grassroots movement for changes in the way librarians communicate with users. This could be because li- brarians are doing just fine at communicating with library users. However, the number of articles dealing with the reference interview by librarians themselves and the number of recent articles on the failure to meet user needs suggest otherwise.

\section{The Role of Language}

One way to examine interactions within the librarian-user and physician-patient dyads is to look at language. As imperfect as language is, it has the power to shape our experience of reality, even at the level of its smallest denominator-the word. Both the medical and library worlds feature many words that are considered technical language. Philip Ley discusses the problems associated with medical jargon in his comprehensive treatise on medical communication, Communicating with Patients: Improving Communication, Satisfaction and Compliance. Ley cites studies that consistently found discrepancies between physicians' and patients' interpretations of common medical terms. ${ }^{4}$

Several physicians have called upon their colleagues to demystify medical terminology in dealing with their patients. ${ }^{5}$ Timothy Anderson and David Helm link the use of jargon to the physician's desire to control the interaction:

Language is often used to mystify, to desexualize, to confuse and intimidate the patient, as well as to reaffirm expertise... It is through language that social realities are constructed, and through the expression of language that realities can be negotiated. The physician gains in power through his or her access to and control over the "legitimate" language of health and illness. Thus patients are urged in their presentation of symptoms and problems to recast their accounts in the appropriate nomenclature-which reinforces the 
physician's mandate to determine the reality. ${ }^{6}$

\section{Schema Theory}

Only part of the patient's comprehension problem can be explained by lack of familiarity with word meanings. A patient will interpret what a physician says in terms of the patient's own framework of ideas about illness. This concept relates to what cognitive psychologists call "schema theory." Although not using that term, John Locke gave a good description of schema theory in 1689 in his Essay Concerning Human Understanding:

To make Words serviceable to the end of Communication, it is necessary that they excite, in the Hearer, exactly the same Idea, they stand for in the mind of the Speaker. Without this, Men fill one another's Heads with noise and sounds; but convey not thereby their Thoughts, and lay not before one another their Ideas, which is the end of Discourse and Language.?

Years later, Terry Winograd designed a model of communication (see figure 1) to illustrate schema theory. Briefly, the two participants, the speaker and the hearer, each possess a set of stored schemas, which are collections of knowledge related to a concept. The hearer considers the context of the message and compares it to existing schemas. In addition, each participant has a model of the other person, which may consist of opinions about the actual known individual or notions related to personal characteristics such as appearance, gender, occupation, and so forth. ${ }^{8}$

If the content of the discourse seems familiar, the hearer reacts the same way he or she did before. If the hearer's schemas differ enough from those of the speaker, the intended message is likely to be received incorrectly. This theory explains in part the problems that result from patients not having the underlying medical schemas to understand the terms used by their physicians. The same can be said for library users, who often do not share the library schemas so familiar to reference librarians.

As much as librarians would like to believe that they eschew jargon, recorded reference interviews show that they use jargon in dealing with library users. A study that Joan Stein and I conducted at Carnegie Mellon University revealed that half the time library users did not understand the terms librarians used. In the study, freshmen incorrectly answered multiple choice definitions of library terms such as citation at a rate of 49 percent. Because it appears, based on this research, that library terms do not fall within library users' existing schemas, librarians must take steps to compensate for this communication barrier. ${ }^{9}$

\section{The Power Perspective}

Literature cited throughout this article suggests that many physicians emphasize their authority, assert opinions as if they were dogma, maintain emotional distance, discourage patient collaboration,

As much as librarians would like to believe that they eschew jargon, recorded reference interviews show that they use jargon in dealing with library users.

and promote poor communication with patients. Why? One reason involves a desire for control and power. ${ }^{10}$

In general, the physician wields power in the interaction by controlling the discussion and monitoring the amount and type of information given to the patient. This is known as expert power, the use of possessed knowledge to control others. It only works so long as the expert (doctor) can keep the patient from obtaining comparable expertise. ${ }^{11}$

If the physician retains control of the knowledge, the physician has a dominant role to the subordinate patient. As one 


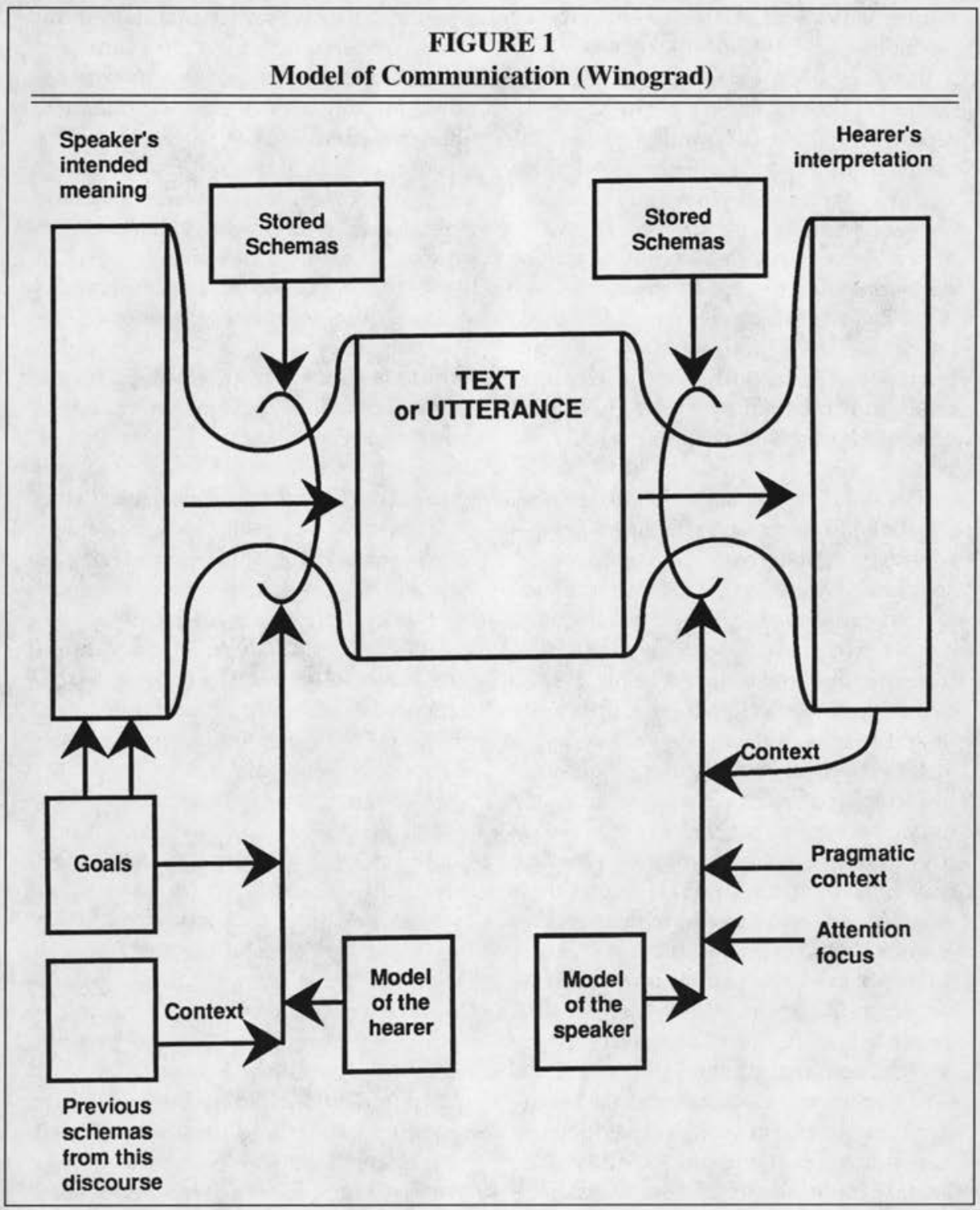

communication studies writer explained, "People have been socialized into expecting both minimal interpersonal rapport with most health professionals and maximal control, from them." 12 This type of relationship, which the reader might view as paternalistic, may be common, but it may not be what the patient wants or needs.
A patient who deviates from the expected silent role may suffer consequences, according to some authors. In one hospital study entitled "Good Patients and Problem Patients," Judith Lorber addressed the issue of patients' reactions to physicians' expert power. Physicians considered patients who refuse to be submissive or to follow the 
informal rules of the institution to be problem patients who place more demands on busy physicians. Lorber concluded that health professionals used medical neglect to "punish" these patients for their nonconformity. ${ }^{13}$

Some writers have urged physicians to reexamine their use of expert power, which they claim is detrimental to physicians, to patients, and to their relationships. Judith Rodin and Irving Janis called for physicians to use, instead, "referent power," the motivating power that derives from a person's ability to be likeable, benevolent, admirable, and accepting. ${ }^{14}$

The issue of power and control relates somewhat differently to the library environment. Although librarians possess specialized knowledge and therefore expert power, they are not awarded the high income that many physicians receive. Income, status, and self-image are issues that one encounters regularly in library literature.

If the use of power in an occupation is linked to the rewards of professionalism, researchers should not be surprised to see controlling behavior exhibited by reference librarians. The reference interview may serve as a means for control by the reference librarian. A number of library articles have examined one aspect of control centering on the information-versusinstruction debate. This debate, now over thirty years old, features on one side those who see librarians as intermediaries involved in every step of providing users with information and, on the other side, those who advocate self-reliance of library users by teaching them how to find information by themselves. ${ }^{15}$ There may be correlations between the attitude that encourages users to depend on the librarian for their information needs and the attitude of the physician who controls the dissemination of information.

Two other points made with relation to medicine may have relevance to the library. First, the concern expressed about relegating the demanding patient to the role of "problem patient" and limiting communication certainly has its correlation. At a busy reference desk, a reference librarian might have a similar negative reaction to a verbose, more demanding user. The second important point is the emphasis of referent power over expert power. Users might be more receptive to the likeable, accepting communication style that typifies referent power.

\section{Outcome of Communication Failure}

When the patient or library user cannot comprehend the information that has been given to him or her, or cannot recall or use it, or is so dissatisfied with the interaction that he or she does not return, then harm has been done. Medical articles have investigated the negative outcomes of communication failure. Articles studying the independent variable of communication focus on its effect on four dependent variables: recall of information, compliance with instructions, medical outcome or success, and satisfaction.

\section{Recall}

Recall is very important in medicine because, unlike most library situations, individuals acquire information and then leave with the expectation that they will recall what they have learned and follow the instructions at home. Thus, recall is linked to what physicians call "compliance."

In a study of medical terminology, Lyle Saunders and Richard Larson found that patients were unable to recall medical terms that they did not understand. They concluded:

Health practitioners who have facility with medical terms can think faster about medical topics than the patients with whom they are talking. In a discussion the practitioner may have gone on to a new topic while the patient is still trying to remember precisely what "abdomen" 
means. Second, practitioners may be better able to remember past discussions and problems than patients because of their greater knowledge of medical language. The patient may have forgotten the explanation received at the last visit because all the terms were new to the patient. ${ }^{16}$

In other words, the fact that patient and physician do not share the same schemas impedes the patient's recall of instructions. Ley's study of patient recall found that patients fail to recall many of the instructions and information they receive. In fact, he found that the number of statements that patients forget increases with the number of statements presented. Neither age nor intelligence is consistently related to recall, but existing medical knowledge (schemas) do increase recall. Ley discovered that order is related to recall, with the last items presented being the ones best recalled. He also concluded that the amount people recall can be influenced by shorter words and sentences,

\section{... recall could be enhanced if the librarian uses shorter words and sentences, explicitly categorizes types of information presented, repeats information, and is specific and concrete.}

by explicit categorization, by repetition, and by use of concrete language rather than abstract language. Anxiety has a negative effect on recall, with very low or very high anxiety increasing recall problems. ${ }^{17}$

Other researchers have studied recall problems in terms of the communication process. One study found that half the instructional statements patients received and two-thirds of the statements dealing with diagnosis or treatment were forgotten and that, in general, there was no connection between the loss of information and the passage of time. ${ }^{18}$
How do these findings pertain to librarianship? Recall has not been heavily researched in the library field, as represented by the Library Literature and ERIC (education) bibliographic indexes. The findings described above could be instructive to reference staff, who would like library users to recall the information they give them. For instance, recall could be enhanced if the librarian uses shorter words and sentences, explicitly categorizes types of information presented, repeats information, and is specific and concrete.

\section{Compliance}

The second variable affected by communication problems is compliance. Compliance has been a major source of concern in the medical world for many years. One physician suggests that the word itself denotes "orders" followed by "good" patients. He argues that physicians should not use communication to persuade but, rather, to outline possible plans of action so that self-reliant patients can make their own informed choices, for which they will be responsible for the consequences. ${ }^{19}$

Several possible reasons exist for patient noncompliance. As mentioned earlier, the patient's inability to recall the information is one reason. The patient might also be so dissatisfied with the interview, the doctor, or the suggested treatment that he or she ignores the instructions. Another reason might be a lack of understanding. The doctor may not have conveyed the instructions clearly, or the patient's schemas of experience vary too much with the message. Health care treatments are often complex, and concepts and terms are often new to patients, who may, instead, call upon their own existing schemas with regard to illness. Comprehension problems may result from the patients' inability to comply with the physician's suggestions.

Noncompliance may be unintentional or intentional. Analee Beisecker, in an article entitled "Patient Power in Doctor-Pa- 
tient Communication," suggests that patients may modify the prescribed treatment as a way to assert their independence and power. She states, "It should be noted, however, that in some cases, the modified treatment regimens are preferable to those prescribed by physicians, because patients are in tune with their own bodies and can perhaps determine a more appropriate dosage of medication than a physician applying standard protocols." 20

Kathryn Rost and other researchers examined the exchange of information in relation to patient compliance. The study reviewed the intake interviews of fortyfive patients. When they compared physicians' discourse styles with compliance, they concluded that "exchange that allows the emergence during the examination of both the physician's and patient's perspective co-occurs with (if not influences) a patient's decision to follow through with recommendations made during the visit." ${ }^{21}$

The authors also suggest that if patients provide information that doctors request and volunteer additional information, the partnership will be more likely to arrive at a definition of the problem that both partners share. Teaching physicians to invite patient input may enhance outcomes, according to the study.

Library literature has not addressed this problem of noncompliance. Librarians advise and instruct users, and because they are often physically nearby as users carry out their tasks, there is a sense that users are following through on their directions. Unlike physicians, librarians benefit from this proximity, as they are more readily available for additional clarification and any follow-up questions or concerns. Nevertheless, it would be interesting to observe how library users actually implement, or ignore, librarians' suggestions. Given these medical findings on recall, the librarian concerned with users following through on instructions should think of the interview as an exchange, with both partners working to define and solve a shared problem.

\section{Ultimate Outcome or Success}

The effect of communication on the ultimate outcome of the medical or library intervention is of obvious interest to practitioners. Researchers found some connection between patient-physician communication and compliance, and medicine assumes a strong connection between a patient's compliance with a medical regimen and symptom relief. A number of researchers have noted improvement in patients (e.g., quicker recovery time, symptom relief) stemming from improved compliance resulting from better communication between physician and patient. Based on these articles, increased physician responsiveness and the encouragement of patient involvement brought about improved communication. ${ }^{22}$

One study on outcome, written by Sheldon Greenfield, found significant improvements in patients' physical functioning after they received training in communication techniques designed to increase their involvement in their own care. The study consisted of an experimental group and a control group of patients with ulcers. Researchers taught patients in the experimental group to read their own medical records and coached the patients to ask questions and negotiate decisions. After the training, patients were more assertive and more involved with the physician during the medical interview. Eight weeks later, patients in the experimental group expressed more satisfaction with their care than the control group, preferred a more active role in decision making, and reported fewer physical limitations. ${ }^{23}$

Beisecker also observed changes in patients who were encouraged by researchers to take a more active role in the medical interview. The patients she observed expressed opinions, asked questions, had a better understanding of their treatment, and appeared better able to 
follow the treatment, leading to better medical outcomes. ${ }^{24}$

In library literature, studies of ultimate outcome focus primarily on reference librarians' success in answering questions accurately. Accuracy measures consistently have found problems in terms of librarians providing library users with correct information. A number of research studies using unobtrusive testing indicate that librarians provide the correct answer only about 55 percent of the time. ${ }^{25}$

Observers in the Durrance study
were far more forgiving when
library staff members had weak
interviewing skills or gave inaccu-
rate answers than if the staff
member made them feel uncomfort-
able, showed no interest, or ap-
peared to be judgmental about the
question.

Undoubtedly, these studies alarmed many librarians. Improving reference accuracy is an aim that concerns reference librarians and administrators. Some libraries have been successful in their conscious efforts to raise staff accuracy rates. For example, Ralph Gers and Lillie Seward studied Maryland public libraries and focused on the variable of feedback. According to the study, librarians who did not solicit feedback from library users supplied correct answers 52 percent of the time. Librarians who asked for feedback, asking users whether their questions had been answered, were able to provide better assistance, resulting in a 76 percent accuracy rate. ${ }^{26}$

Answer inaccuracy is only part of the problem, however. Physicians can disseminate accurate information and, for various reasons, the patient still may not have a successful outcome. Poor communication techniques may lead to accurate information not getting through to the hearer. Conversely, good communication techniques can actually result in a satisfied hearer even if the content of the information is not very accurate.

One author, Joan Durrance, raised the question, "Does the 55 percent rule tell the whole story?" Durrance reported on a study in which observers rated 266 librarians in terms of their reference interview skills. Results consistently showed that subjects who gave high scores to the librarians on the interpersonal variables of comfort, friendliness, and interest were almost certain to return to the same library staff member. Those who gave a high ranking to librarians on the skill variables of determining need and interviewing ability would also return.

Durrance noted that in terms of skill, the study did bear out what other studies have concluded-that librarians frequently have poor interviewing skills. Observers in the study determined that only 27 percent of the librarians found out what the questioner needed. Other variables, such as a display of interest, were perceived to rank high in importance. $\mathrm{Ob}$ servers in the Durrance study were far more forgiving when library staff members had weak interviewing skills or gave inaccurate answers than if the staff member made them feel uncomfortable, showed no interest, or appeared to be judgmental about the question. This study concluded that accuracy is an important, but not the only, crucial key to the success of the reference interview. ${ }^{27}$

Recently, some libraries began using alternative, more qualitative surveys to evaluate reference service effectively. These methods foster librarian behaviors in a multidimensional way. They measure effectiveness not only in terms of accuracy, but in terms of factors such as availability, question interpretation, and communication. These evaluation instruments are discussed in specific terms that can be adapted by other libraries. ${ }^{28}$

\section{Satisfaction}

The final section of this discussion of outcome is devoted to satisfaction, which is 
really another measure of ultimate outcome or success. In 1968, a team of physicians researched doctor-patient interaction and patient satisfaction with a survey of 800 parents of children in a hospital pediatrics unit. Researchers asked subjects to evaluate the medical interview with their children's physician and to rate their satisfaction level with the physician.

Seventy-six percent of the parents were highly or moderately satisfied. Those who made favorable note of the physician's communication skills (making statements such as "He listened to me," "He explained so well") were dramatically more satisfied than those who disparaged their pediatrician's communication skills. Several unexpected findings emerged. For instance, although parents went in to the interview with specific main worries, only 24 percent of these worries were verbalized to the doctor. Thus, even if they never raised what most concerned them, they were still generally satisfied. The authors raise an interesting point when they say that the measure of patient satisfaction may be suspect "because quacks, faith healers, and so forth are notorious for producing high satisfaction in their clientele, even though the service that is offered is of low quality or dishonest at times." 29

Other researchers found that the amount of informativeness and the display of feelings such as empathy were highly correlated with satisfaction. It is important to note, as several studies did, that patients vary in their preferences for a physician's behavior. Some prefer more directive approaches than others and prefer acquiring information without necessarily accepting responsibility for decision making. ${ }^{30}$

In the library world, some measures of library user satisfaction are part of major evaluation studies. Some authors have questioned the weight ascribed to satisfaction measures. This is because, as was found in one of the medical studies, an individual often expresses satisfaction even if he or she walks away with what might be considered inadequate information. In fact, despite reports of a 55 percent accuracy rate, many user surveys indicate a satisfaction rating for reference service that surpasses 90 percent. $^{31}$

A person's satisfaction level with library staff service can be attributed to attention, a friendly attitude, and a few citations. Thus, satisfaction levels are important because a satisfied user will be more likely to want to return to a given library and librarian. But satisfaction is not enough if the results of research are wanting. If the user leaves the library with inaccurate or insufficient information, it matters little that the person feels satisfied.

Several researchers studied satisfaction in conjunction with user success. Charles Bunge and Marjorie Murfin surveyed both users and librarians at fifteen libraries. In the area of satisfaction, they found that the one factor that led to users becoming more dissatisfied was the degree of busyness of the librarian, leading to brief, one-source transactions. ${ }^{32}$ Bunge and Murfin also found what they considered to be a greater sensitivity to user feelings among successful librarians. In the successful libraries (highest in user success and satisfaction), the librarians were more aware of communication difficulties, reporting difficulties on the same questions where the users reported difficulties.

In summation, medical and library studies have found that good communication skills and sensitivity to communication problems have an effect on patient/user satisfaction. Measuring satisfaction and improving it via improving communication skills would likely benefit any institution, in terms of increasing user return rates and overall positive attitudes.

\section{A Model for Outcome}

The author devotes a good deal of this paper to outcome in the medical and li- 


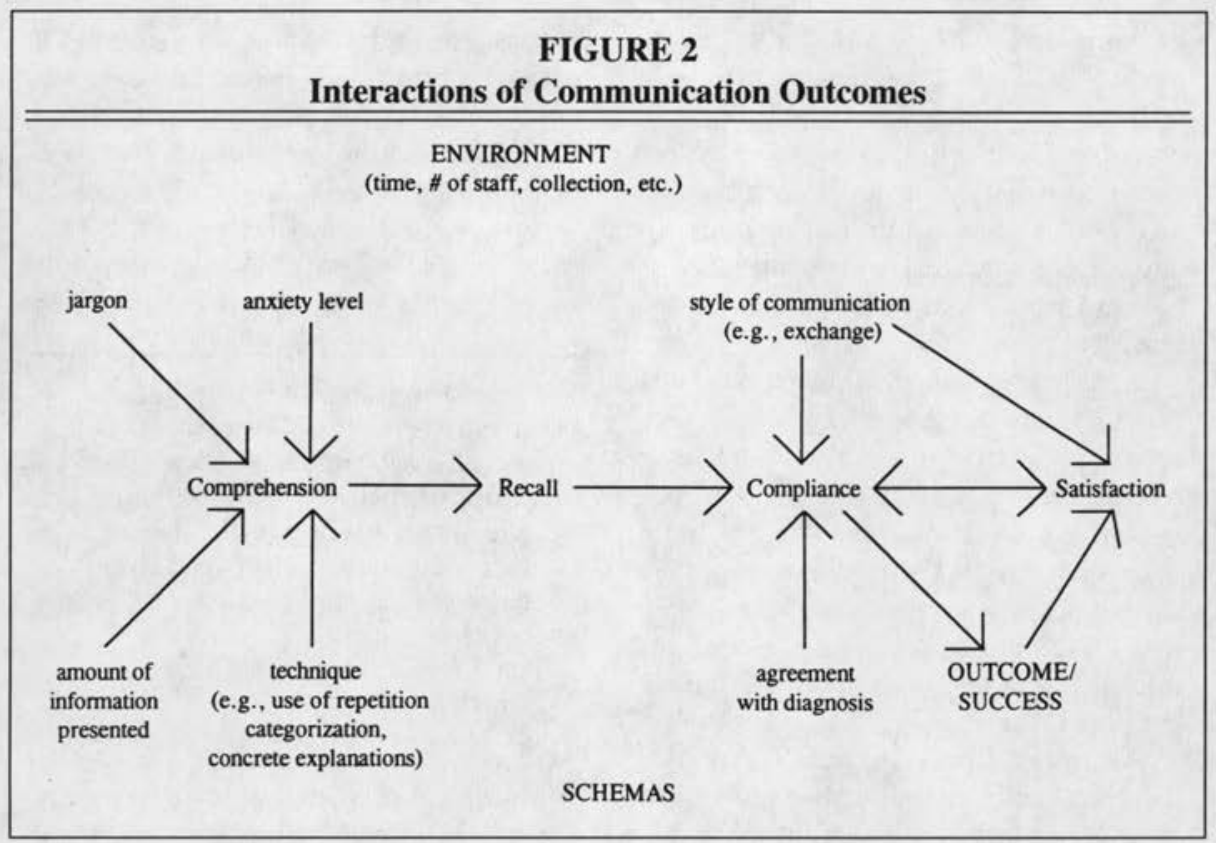

brary settings. Outcome is affected by communication in various ways. Figure 2 summarizes the interactions between the various factors.

The comprehension of the hearer (the patient or the library user) is affected by variables such as the amount of information presented, the hearer's anxiety level, the speaker's use of jargon, and the speaker's techniques, such as use of repetition and categorization of ideas into units that are easier to assimilate. Comprehension affects recall, which affects compliance or the following of instructions.

Recall alone is not always enough to ensure compliance. Other variables that may have an effect on recall are the hearer's agreement with the diagnosis or suggestion, and the speaker's communication style. One type of style that seems to promote compliance is a sharing style, where both parties exchange information. Style also affects satisfaction.

Compliance with a good suggestion usually results in success. Compliance can also lead to a sense of satisfaction. Likewise, satisfaction with an interaction can lead to compliance with instructions. Success certainly leads to satisfaction, and satisfaction can be considered an outcome.

All of this interplay of factors is surrounded by the effects of both parties' existing schemas. In addition, interaction may be affected by the environment, which might consist of waiting library users, the number of staff members, the reference collection, rules and procedures, the ringing of telephones, and so forth.

\section{Enhancing Communication: Techniques and Training}

This paper describes some of the outcomes that medical researchers identified as being associated with communication problems. A number of suggestions are offered for avoiding such problems at the reference desk, thereby improving library users' recall of instructions, ability to comply with suggestions, ultimate outcome or success, and satisfaction.

In terms of specific interview techniques and training, medical articles offer few details. However, they do offer a body of literature demonstrating in study after study that medical students trained 
in interviewing skills conduct more successful medical interviews than students without training. Students with training not only elicit a greater amount of relevant information from patients, but also are better able to communicate empathy and to detect and respond to patients' verbal and nonverbal cues-skills that remain over time. ${ }^{33}$

Several types of teaching seem conducive to the learning of effective interview techniques. In one detailed article on teaching these skills, B.J. Evans and others outline an eleven-hour, eight-session course in medical history-taking. The course heavily emphasizes the use of active learning formats such as discussions, role-plays, and videotaping with real and simulated patients. ${ }^{34}$

Although librarians can learn from these controlled studies, they can probably learn more about techniques and, to a lesser extent, training from their own literature than from medical literature. For example, two far-ranging and practical books on reference interview techniques are Elaine Jennerich's The Reference Interview as a Creative Art and Catherine Ross's and Patricia Dewdney's Communicating Professionally: A How-to-Do-It Manual for Library Applications. These books lay out the foundations for better communication techniques, giving examples that are relevant to the reference encounter. ${ }^{35}$ A number of detailed articles have been written on specific techniques described in the Jennerich and RossDewdney books, such as active listening and the effective opening and closing of the reference interview. ${ }^{36}$ Given that such methods recognized in librarianship are effective interview techniques, how do librarians best learn them? A lengthy discussion of teaching methods cannot be given here, but a few suggestions should be made.

The medical articles cited at the beginning of this section suggested that the poor interviewing techniques of medical students negatively affected patients' out- comes. Through training, often involving active learning such as role-playing, videotaping, and the practicum or internship, their techniques improved and continue to improve.

Library courses that employed the same methods, particularly the use of more than one class session to address

The comprehension of the hearer (the patient or the library user) is affected by variables such as the amount of information presented, the hearer's anxiety level, the speaker's use of jargon, and the speaker's techniques, such as use of repetition and categorization of ideas into units that are easier to assimilate.

communication issues, seem to have similar positive effects on students' interviewing skills. ${ }^{37}$ In general, however, the communication barriers and techniques are only briefly touched upon in library schools. In a recent request via the Internet listserv LIBREF-L for information on the teaching of the reference interview in library schools, the author received a dozen or so lukewarm responses about such lectures. The most enthusiastic librarian comments about classes that prepared them for the real-life reference interview were multisession communication courses such as those offered at the University of Pittsburgh and the University of Michigan.

Interview skills can be taught in the workplace. Libraries employed many varieties of continuing education. Several sites have implemented peer coaching. ${ }^{38}$ A reference coordinator or department head might help alert colleagues to communication techniques. Articles such as those cited in this article could be routed and discussed at meetings. Good videotapes on reference skills could be acquired and shown. The best method is probably a combination of approaches, offered on a fairly regular basis. 
Medicine borrows from other disciplines when designing communication components for courses, according to some sources. Librarians, too, can learn from other professions. Counseling or even medical curricula can be modified for library schools or continuing education sessions. Some library authors write about such applications. ${ }^{39}$

\section{Conclusions}

This paper began with a look at some of the communication problems that physicians themselves have identified in the patient-physician relationship. Others, too, such as advocates of the Plain English movement, have called upon physicians to simplify explanations, avoid undefined jargon, and avoid using language that creates a distance between patient and physician. The physician's language has also been tied to issues of power and control. The negative outcomes of physicians' communication problems are varied and extensive.

These problems and their outcomes are relevant to librarianship, which also features jargon and an environment that seems to lend itself to complex explanations. Like physicians, librarians must choose whether to view the nature of the interview as an opportunity to control information or as an opportunity to exchange information with the library user. I agree with those who urge experts in the medical and library worlds to rethink their relationships to nonexperts, and to work toward the sharing of knowledge using referent power rather than the monopolization of knowledge, which is often typical of expert power.

Some physicians are learning to cultivate skills "that respect patients' intelligence, acknowledge their needs, accept their feelings, value their opinions, and promote collaboration in decision making." 40 The library world also must heighten its awareness of the issues presented here, through library schools placing greater emphasis on interpersonal communication, through on-the-job training, through qualitybased evaluation, and, most important, through a commitment to lower the communication barriers between librarians and library users.

\section{Notes}

1. Carolyn J. Radcliff, "Interpersonal Communications with Library Patrons: Physician-Patient Research Models," RQ 34 (summer 1995): 497-506.

2. Robert S. Taylor, "Question-Negotiation and Information Seeking in Libraries," College \& Research Libraries 29 (May 1968): 180.

3. Lynda M. Baker, "Physician-Patient Communication from the Perspective of Library and Information Science," Bulletin of the Medical Library Association 82 (Jan. 1994): 36-42.

4. Philip Ley, Communicating with Patients: Improving Communication, Satisfaction and Compliance (London: Croom Helm, 1988): 25.

5. Barbara M. Korsch and others, "Gaps in Doctor-Patient Communication," Pediatrics 42 (Nov. 1968): 862; Donna M. Musialowski, "Perceptions of Physicians as a Function of Medical Jargon and Subjects' Authoritarianism," Representative Research in Social Psychology 18 (1988): 314; Barbara Wilson, "Improving Recall of Health Service Information," Clinical Rehabilitation 3 (1989): 275-79; Stuart G. Finder, "Attitudes and Discourse: The Words of Medicine," Journal of the American Medical Association 268 (Nov. 4, 1992): 2449, 2453; Larry Westreich, "Doctors and Language: How We Confuse Our Patients," Journal of the American Medical Association 265 (Jan. 2, 1991): 117.

6. Timothy W. Anderson and David T. Helm, "The Physician-Patient Encounter: A Process of Reality Negotiation," in Patients, Physicians, and Illness: A Sourcebook in Behavioral Science and Health, ed. E. Gartly Jaco (New York: Free Pr., 1979): 266.

7. John Locke, An Essay Concerning Human Understanding (Oxford: Oxford Univ. Pr., 1975). Quoted in Talbot J. Taylor's, "Do You Understand? Criteria of Understanding in Verbal Interaction," Language and Communication 6 (1986): 171. 
8. Terry Winograd, "A Framework for Understanding Discourse," in Cognitive Processes in Comprehension, eds. Marcel Adam Just and Patricia A. Carpenter (Hillsdale, N.J.: Erlbaum, 1977): 63-88. For a good exploration of linguistic processing, see Stuart Glogoff's, "Communication Theory's Role in the Reference Interview," Drexel Library Quarterly 19 (spring 1983): 56-72. For a discussion of schema theory as it relates to libraries, see Barbara Doyle-Wilch and Marian I. Miller's "Mediation and Schemata Theory in Meaningful Learning: The Academic Librarian's Role in the Educational Process," Reference Librarian 37 (1992): 121-27.

9. Rachael Naismith and Joan Stein, "Library Jargon: Student Comprehension of Technical Language Used by Librarians," College \& Research Libraries 50 (Sept. 1989): 543-52.

10. Dean C. Barnlund, "The Mystification of Meaning: Doctor-Patient Encounters," Journal of Medical Education 51 (Sept. 1976): 722.

11. John Cullen, The Structure of Professionalism (New York: Princeton, 1978): 180; Frank H. Spaulding, "Image of the Librarian/ Information Professional; A Special Libraries Association Presidential Task Force," IFLA Journal 15 (1989): 321; Judith Rodin and Irving L. Janis, "The Social Power of Health-Case Practitioners As Agents of Change," Journal of Social Issues 35 (1979): 60-81; John Thibaut, The Social Psychology of Groups (New York: Wiley, 1959): 109.

12. Paul Arntson and David Droge, "Addressing the Value Dimension of Health Communication: A Social Science Perspective," Journal of Applied Communication Research 16 (1988): 6.

13. Judith Lorber, "Good Patients and Problem Patients: Conformity and Deviance in a General Hospital," Journal of Health and Social Behavior 16 (June 1975): 74-76.

14. Rodin and Janis, "The Social Power of Health-Care Practitioners as Agents of Change."

15. Many articles have been written on this topic, including: Brian Nielson, "Teacher or Intermediary," 183-89; James Rettig, "Self-Determining Information Seekers," RQ 32 (winter 1992): 156-63; James Rice, "Library-Use Instruction with Individual Users: Should Instruction Be Included in the Reference Interview?" Reference Librarian 10 (spring/summer 1984): 75-84.

16. Lyle Saunders and Richard F. Larson, "Medical Vocabulary Knowledge among Hospital Patients," Journal of Health and Human Behavior 2 (summer 1961): 86-87.

17. Philip Ley, "Memory for Medical Information," British Journal of Social and Clinical Psychology 18 (1979) ): 252-53.

18. C. R. B. Joyce, and others, "Quantitative Study of Doctor-Patient Communication," Quarterly Journal of Medicine, New Series 38 (1969): 192.

19. Warner V. Slack, "The Patient's Right to Decide," Lancet 2 (July 30, 1977): 240.

20. Analee E. Beisecker, "Patient Power in Doctor-Patient Communication: What Do We Know?" Health Communication 2 (1990): 109.

21. Kathryn Rost, William Carter, and Thomas Inue, "Introduction of Information During the Initial Medical Visit: Consequences for Patient Follow-Through with Physician Recommendations for Medication," Social Science and Medicine 28 (1989): 321.

22. William B. Stiles, "Evaluating Medical Interview Process Components: Null Correlations with Outcomes May Be Misleading," Medical Care 27 (Feb. 1989): 212-20; Sheldon Greenfield, Sherrie Kaplan and John E. Ware, "Expanding Patient Involvement in Care: Effects on Patient Outcomes," Annals of Internal Medicine 102 (1985): 520-28.

23. Greenfield and others, Ibid, 526.

24. Beisecker, "Patient Power in Doctor-Patient Communication," 117.

25. Ralph Gers and Lillie J. Seward, "Improving Reference Performance: Results of a Statewide Study," Library Journal 110 (Nov. 1, 1985): 32-35; Peter Hernon and Charles McClure, "Unobtrusive Reference Testing: The 55\% Rule," Library Journal 111 (1986): 37-41; Peter Hernon and Charles McClure, "Library Reference Service: An Unrecognized Crisis-A Symposium," Journal of Academic Librarianship 13 (May 1987): 69-80; Charles A. Bunge and Marjorie E. Murfin, "Reference Questions-Data from the Field," RQ 27 (fall 1987): 15-18.

26. Gers and Seward, "Improving Reference Performance."

27. Joan C. Durrance, "Reference Success: Does the 55 Percent Rule Tell the Whole Story?" Library Journal 114 (Apr. 15, 1989): 35-36.

28. Carole A. Larson and Laura K. Dickson, "Developing Behavioral Desk Performance Standards," RQ 33 (spring 1994): 349-57; Terry L. Weech, "Who's Giving All Those Wrong Answers? Direct Service and Reference Personnel Evaluation," Reference Librarian 11 (fall/winter 1984): 109-22; David A. Tyckoson, "Wrong Questions, Wrong Answers: Behavioral vs. Factual Evaluation of Reference Service," Reference Librarian 38 (1992): 151-73; Evaluation of Public Services Personnel, ed. Bryce Allen. (Urbana: Univ. of Illinois, 1991); Janet Dagenais Brown, "Using Quality Concepts to Improve Reference Services," College \& Research Libraries 55 (May 1994): 211-19.

29. Barbara M. Korsch, Ethel K. Gozzi, and Vida Francis, "Gaps in Doctor-Patient Interaction and Patient Satisfaction," Pediatrics 42 (Nov. 1968): 866. 
30. Analee E. Beisecker and Thomas D. Beisecker, "Patient Information-Seeking Behaviors When Communicating with Doctors," Medical Care 28 (Jan. 1990): 19-28; Richard L. Street Jr., "Analyzing Communication in Medical Consultations," Medical Care 30 (Nov. 1992): 976-88.

31. Tyckoson, "Wrong Questions, Wrong Answers," 38; P. J. Hansel, "Unobtrusive Evaluation: An Administrative Learning Experience," Reference Librarian 19 (1987): 315-25.

32. Bunge and Murfin, "Reference Questions-Data from the Field," RQ 27 (fall 1987): 15-18.

33. D.R. Rutter and G.P. Maguire, "History-taking for Medical Students II - Evaluation of a Training Programme," Lancet 11 (1976): 558-60; G. P. Maguire, D. Clarke, and B. Jolley, "An Experimental Comparison of Three Courses in History-taking Skills for Medical Students," Medical Education 11 (1977): 175-82; G. P. Maguire, P. Roe, D. Goldberg, and others, "The Value of Feedback in Teaching Interviewing Skills to Medical Students," Postgraduate Medicine 8 (1978): 695-704; A. Werner and J. M. Schneider, "Teaching Medical Students Interactional Skills," New England Journal of Medicine 290 (1974): 1,232-37; A. D. Pool and R. W. Sanson-Fisher, "Understanding the Patient: A Neglected Aspect of Medical Education," Social Science and Medicine 13 (1979): 37-43; C. M. Engler and others, "Medical Student Acquisition and Retention of Communication and Interviewing Skills," Journal of Medical Education 56 (1981): 572-79; G. Alroy, R. Ber, and D. Kramer, "An Evaluation of the Short-term Effects of an Interpersonal Skills Course," Medical Education 18 (1984): 85-89; B. J. Evans and others, "Measuring Medical Students' Communication Skills: Development and Evaluation of an Interview Rating Scale," Psychology and Health 6 (1992): 213-25.

34. B. J. Evans and others, "Lectures and Skills Workshops as Teaching Formats in a Historytaking Course for Medical Students," Medical Education 23 (1989): 364-70.

35. Elaine Zaremba Jennerich, The Reference Interview as a Creative Art (Littleton, Colo.: Libraries Unlimited, 1987); Catherine Sheldrick Ross and Patricia Dewdney, Communicating Professionally: A How-to-Do-It Manual for Librarians (New York: Neal-Schuman, 1989).

36. Nathan M. Smith and Stephen D. Fitt, "Active Listening at the Reference Desk," RQ 21 (spring 1982): 247-49; Thomas P. Peck, "Counseling Skills Applied to Reference Services," RQ 14 (spring 1975): 233-35. For interesting articles that discuss listening and negotiating the user's first question, see Thomas Lee Eichman, "The Complex Nature of Opening Reference Questions," RQ 17 (spring 1978): 212-22; Geraldine B. King, "Open and Closed Questions: The Reference Interview," RQ 12 (winter 1972): 157-60; Brenda Dervin and Patricia Dewdney, "Neutral Questioning: A New Approach to the Reference Interview," RQ 25 (summer 1986): 506-13; Christopher W. Nolan, "Closing the Reference Interview: Implications for Policy and Practice," RQ 31 (summer 1992): 513-23.

37. Marsha D. Broadway and Nathan M. Smith, "Basic Reference Courses in ALA-Accredited Library Schools," Reference Librarian 25/26 (1989): 431-48; Robert E. Brundin, "The Place of the Practicum in Teaching Reference Interview Techniques," Reference Librarian 25/ 26 (1989): 449-64; Edward J. Jennerich and Elaine Zaremba Jennerich, "Teaching the Reference Interview," Journal of Education for $\mathrm{Li}$ brarianship 17 (fall 1976): 107-11; W. Bernard Lukenbill, "Teaching Helping Relationship Concepts in the Reference Process," Journal of Education for Librarianship 18 (summer 1977): 110-20.

38. Schwartz and Eakin, "Reference Service Standards, Performance Criteria, and Evaluation," 4-8; Ralph Gers and Lillie J. Seward, "I Heard You Say ... Peer Coaching for More Effective Reference Service," RQ 22 (1988): 24560.

39. Barron Holland, "Updating Library Reference Services through Training for Interpersonal Competence," RQ 17 (spring 1978): 20711; Peck, "Counseling Skills Applied to Reference Services."

40. Barnlund, "The Mystification of Meaning," 723.

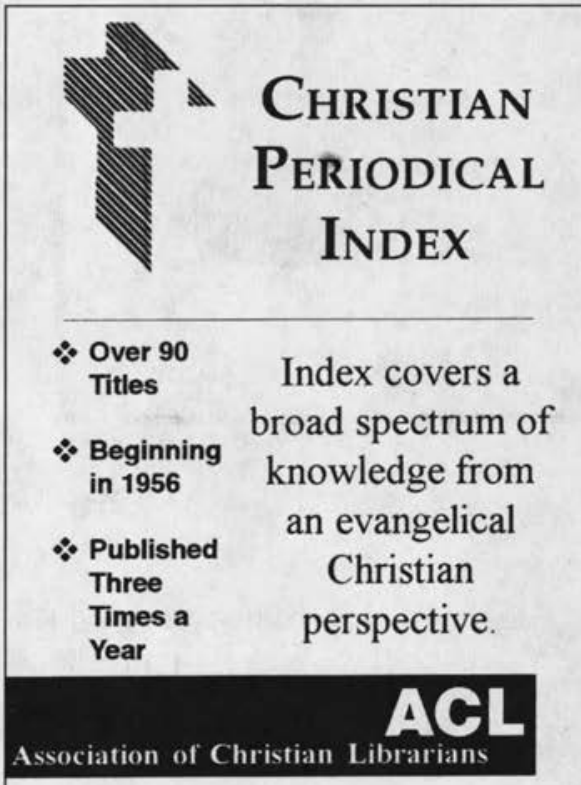

P. O. Box 4 Cedarville, OH 45314-0004 


\section{The State}

of the Art

...working

smart

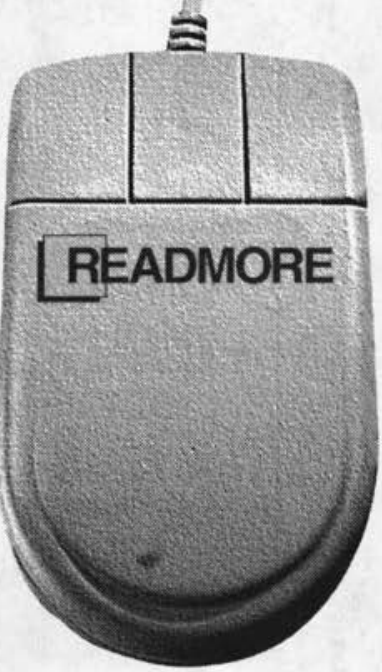

Leaders in the Information

Industry providing subscription services, article delivery and library automation software.

- REMo Mouse driven serials management system.

- Ross Online ordering, claiming and searching of journal and publisher databases.

- Renewal Express PC-based system to analyze current serials holdings and plan for the future collection development.

- Financial Planner Lotus formatted worksheet to analyze previous spending history and plan future budget allocations.

- UnCover The fastest most comprehensive service for fax delivery of journal articles available today.

- BaCKSERV An Internet list devoted to the informal exchange of serial back issues among libraries.

\section{Readmore Academic Services}

700 Black Horse Pike, Suite 207

Blackwood, NJ 08012

Phone: 1-800-645-6595

Fax: 609-227-8322 